\title{
THE CORRECTION OF FACIAL PROGNATHISM
}

\author{
Brigadier J. H. ROBERTSON, Q.H.D.S., F.D.S., R.C.S. (Edin.) \\ Colonel E. S. FOSTER, F.D.S. R.C.S. (Eng. et Edin.), D.Orth.
}

SUMMARY: Operations are described for the correction of facial prognathism. These procedures improve facial appearance and masticatory function.

\section{Introduction}

This condition is not rare, but until relatively recently surgical correction was rarely attempted. Modern anaesthesia and antibiotics reduce the hazards of these procedures which, although they correct or improve masticatory function etc., are from the patient's point of view mainly cosmetic surgery.

Patients are referred by medical and dental practitioners for an opinion regarding possible surgery to correct their deformity. The reasons given include inability or difficulty in masticating food, pain, discomfort or derangement of the temporo-mandibular joint, abnormalities of speech and aesthetic considerations.

Whatever reasons are put forward and regardless of their validity, a short conversation with the patient confirms in the majority of cases that appearance has been the real initiating factor. Ridicule from companions, real or imagined derogatory remarks by other people in a gathering, shyness, particularly with the opposite sex, or the desire to be normal can create a psychological state of sufficient importance for aesthetics alone to be an adequate reason for operation.

Some of our patients of both sexes have been married with families, yet have finally been driven to seek surgical help because of a deeply-seated hatred of their abnormal profile. In our view males are just as sensitive as females about their abnormality.

\section{Mandibular progmathism}

There are several surgical techniques to correct this abnormality but we find that two operations are most suitable for our requirements.

\section{The vertical sub-sigmoid ostectomy}

This is the division and removal of a piece of bone from the vertical ramus of the mandible behind the lingula. This is approached from a submandibular incision in one of the neck creases. The insertions of the masseter and medial pterygoid muscles are detached from the ramus, a planned section of bone is removed from the vertical ramus and the mandible pushed back to normal position. If the prognathism is more than $10 \mathrm{~mm}$ or, if there is an anterior open bite, a hinge fracture of the coronoid process of the mandible must be made to counteract the tendency of the temporalis muscle to cause relapse (Fig. 1). Intermaxillary fixation is applied.

The neck scar would appear to be a disadvantage but when the incision is meticulously repaired the resultant scar is practically invisible within a year.

Sagittal split operation of the vertical ramus (Obwegeser's operation)

The approach to this operation is intra-oral, access is more difficult and in our view a more hazardous procedure. The vertical ramus is split sagitally and the main fragment 

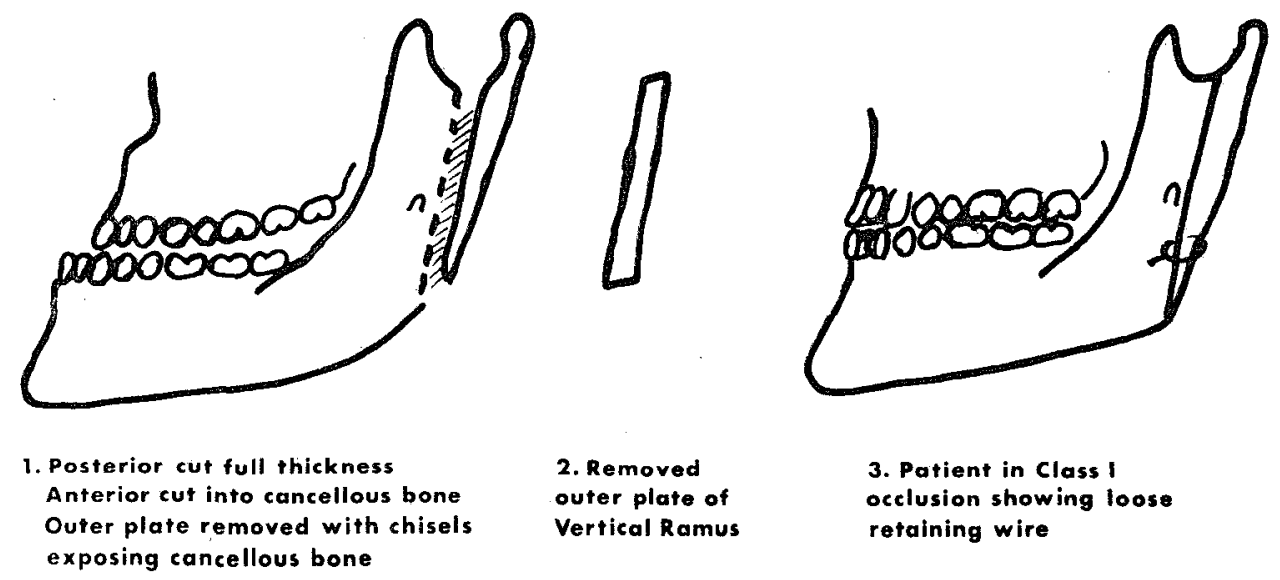

2. Removed outer plate of Vertical Ramus
3. Patient in Class occlusion showing loose retaining wire

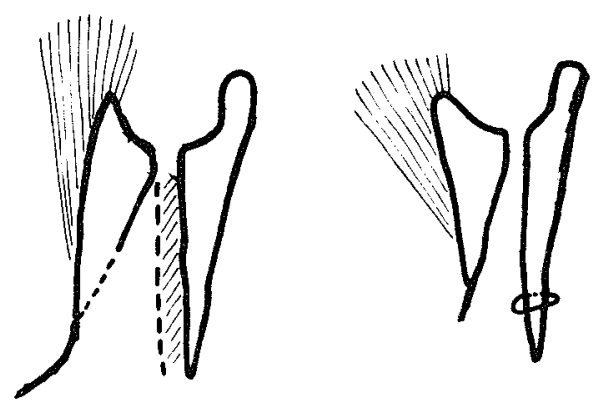

4. Where push-back is in excess of $8-10 \mathrm{~mm}$ or where there is an associated open bite hinge fracture of coronoid process it is essential to counteract relapsing action of Temporalis muscle

Fig. 1. Vertical sub-sigmoid ostectomy.

pushed back into its selected position. This operation is also used to advance a retrognathic mandible to normal position (Fig. 2). Intermaxillary fixation is applied.

\section{Maxillary prognathism}

Patients complain of protruding upper incisor teeth. This can often be corrected by orthodontic treatment. However, in adult life such treatment is prolonged and patients do object to wearing appliances. Surgical correction is of special value in the Army as many patients are frequently posted at relatively short intervals.

Surgically this condition is corrected by extracting one or two premolars on both sides and dividing the maxilla vertically and then obliquely forward to the pyriform fossa. Then a segment of bone equivalent to the amount of push-back necessary is removed sub-periosteally from the bony palate. The anterior nasal spine is split off, the lower end of the nasal septum is divided and occasionally a section must be removed. Occasionally the anterior segment of the palate must be divided to re-align the incisor and canine teeth and to put them in the correct relationship to the lower anterior teeth (Fig. 3). No intermaxillary fixation is required but a three part maxillary splint must be worn for six weeks. In addition Obwegeser's operation to advance the mandible is sometimes necessary. 


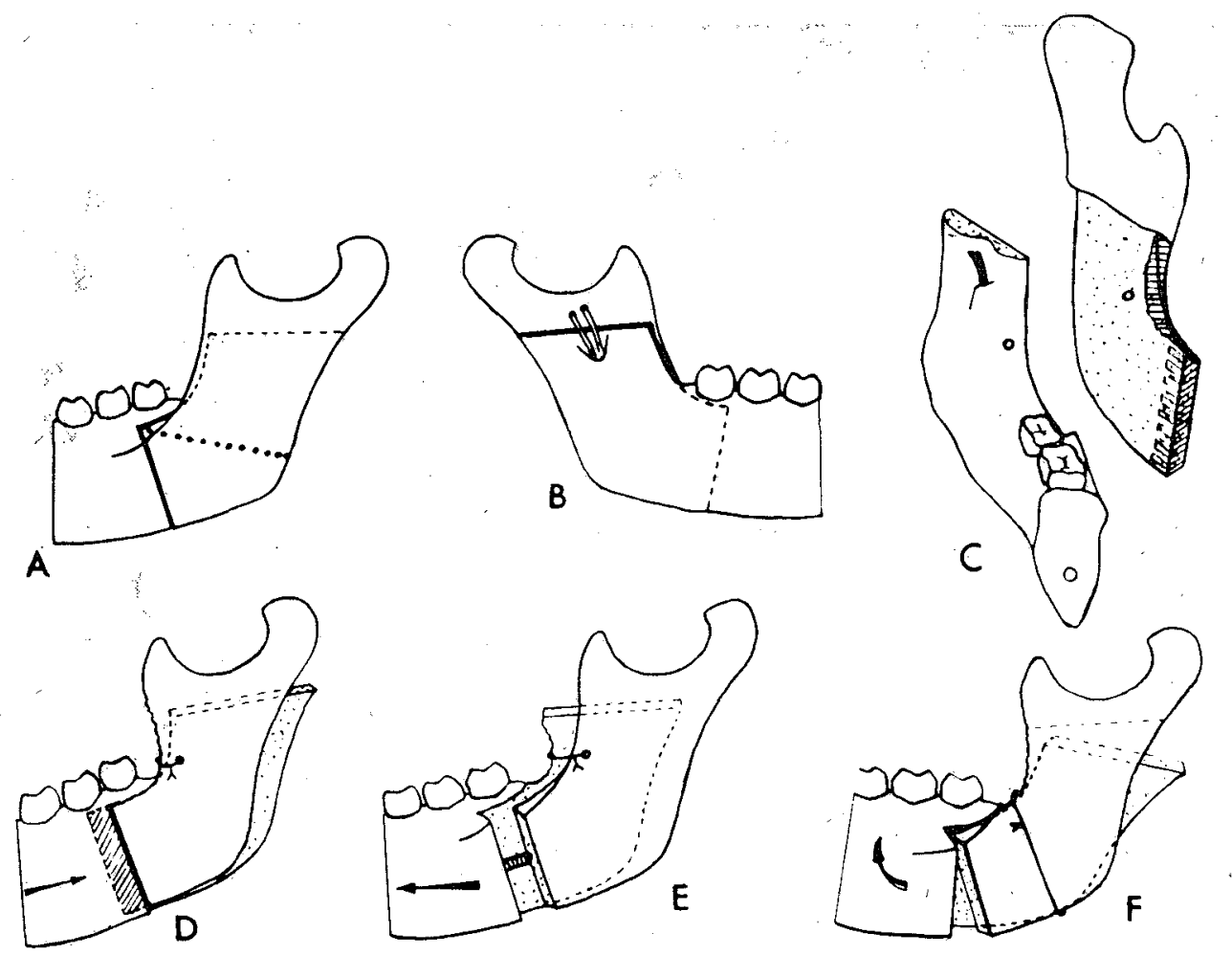

(Brit. J. Oral. Surg. 1. By permission of the Editor and publishers E. \& S. Livingstone Ltd.)

Fig. 2. Obwegeser's sagittal splitting technique of the ramus $(a-c)$ for correction of mandibular prognathism (d), retrusion (e), and open bite (f).

\section{Assessment}

For planning and record purposes radiographs of the facial bones, photographs full face, profile and of the teeth in their present occlusion are required. Two sets of plaster of paris models of the teeth and their supporting structures are made. Using the radiographs, photographs and models, the operation is planned.

The major nature of the surgery, the amount of postoperative discomfort and the postoperative fixation period is fully explained to the patient. He or she goes off to consider the matter further and to discuss it with relatives. If possible we let them discuss it with patients who have had such an operation. Very few patients fail to return for surgery.

\section{Pre-operative procedure}

When the patient returns for operation, orthodontic treatment, cusp reduction of teeth and removal of malposed teeth is carried out as necessary. Acrylic resin cap splints are cemented on the teeth. Blood is taken for cross matching but transfusion is rarely necessary. Old scars are examined for any signs of keloid formation; this has great influence on the type of operation selected. Antibiotic therapy is started and usually continues for five to seven days. 

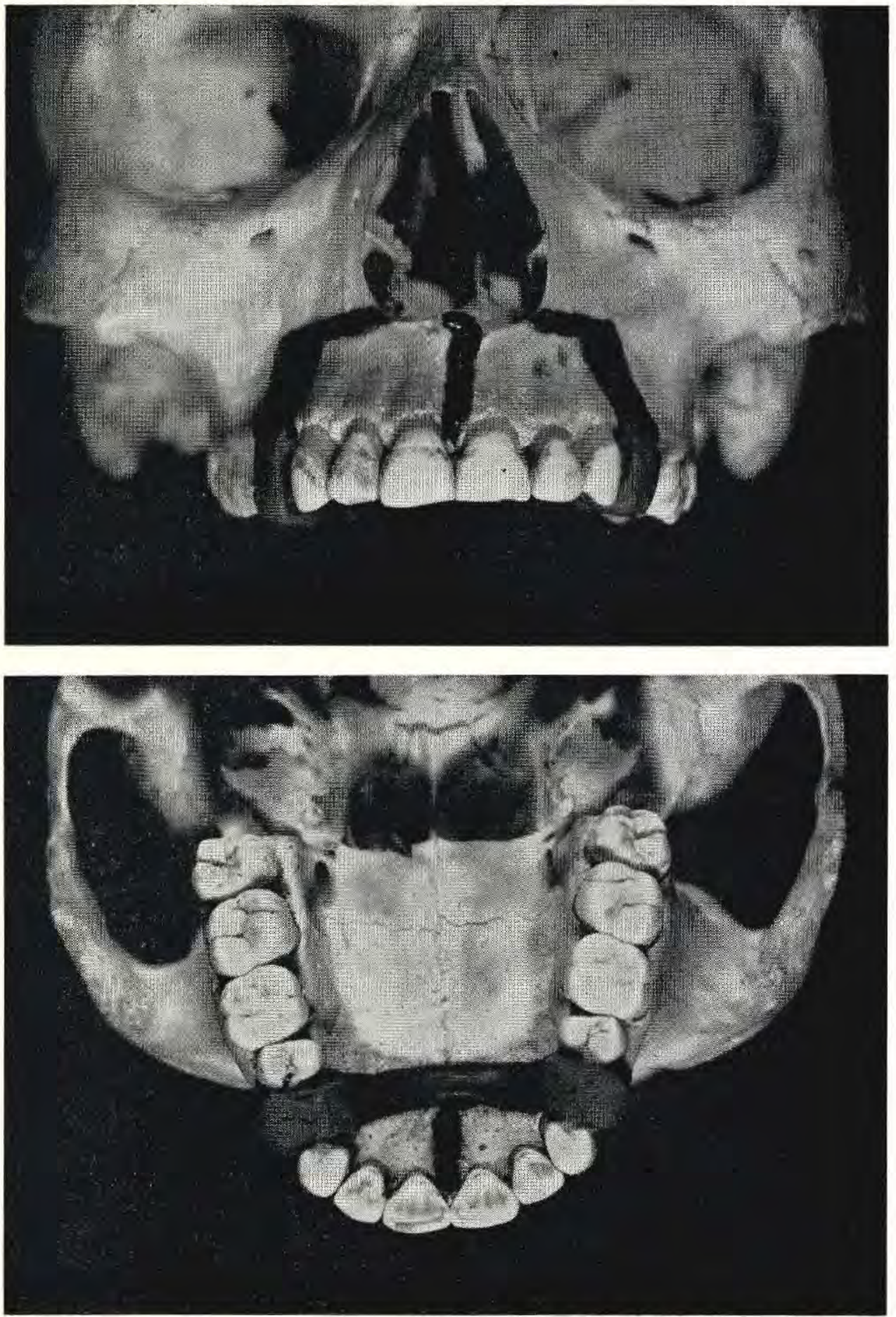

(By permission of Messrs, P. R. Barton and J. Rayne).

Fig. 3. Maxillary ostectomy. 

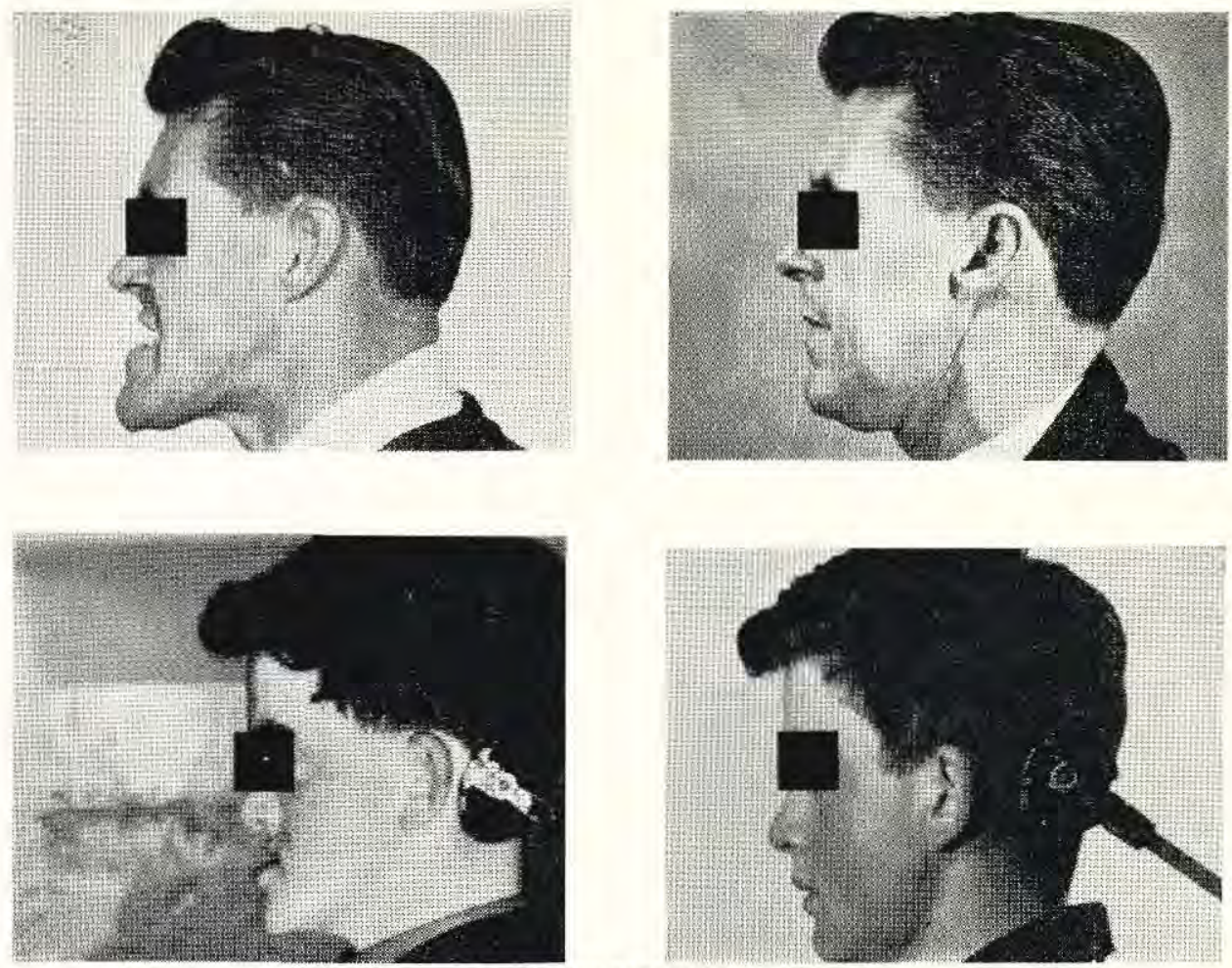

Mandibular prognathism.
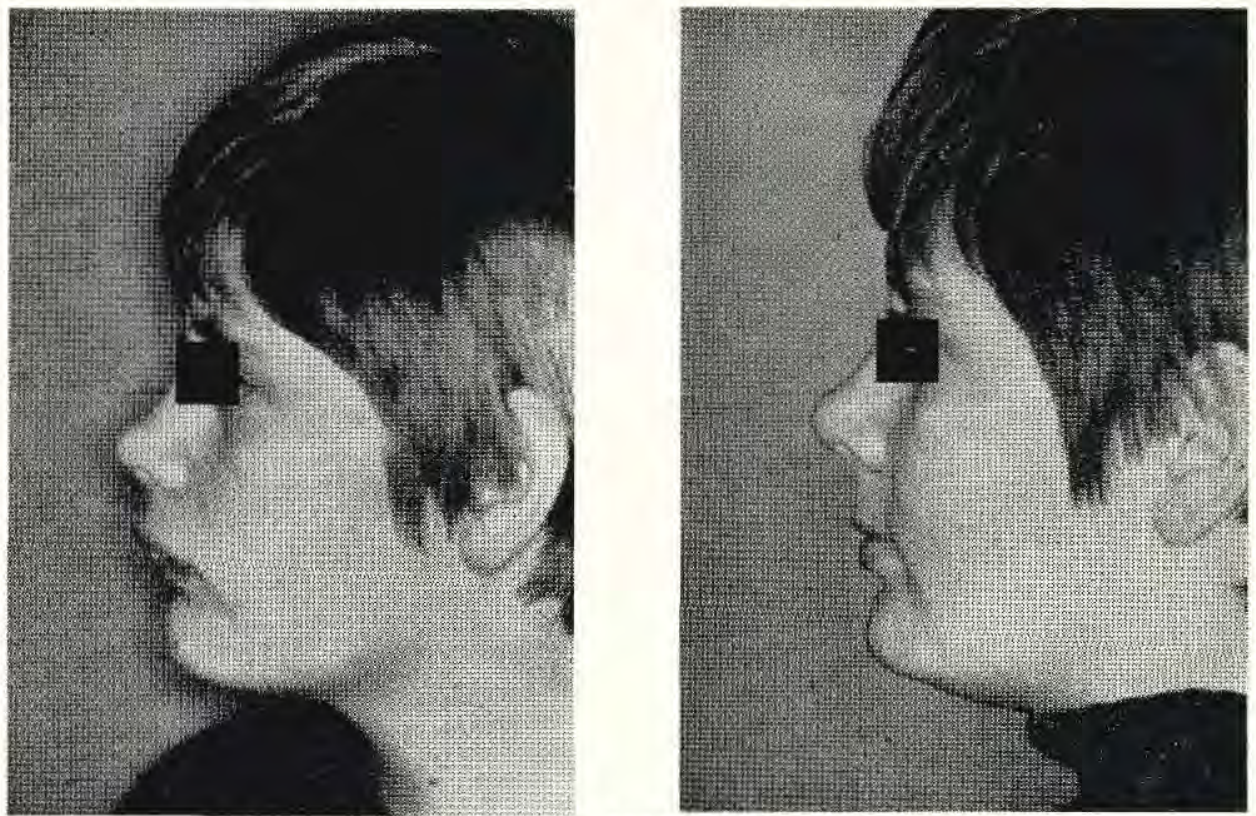

Maxillary prognathism.

Fig. 4. Results of treatment, 


\section{Operation}

Operation is under endotracheal anaesthesia. A dextrose saline drip is set up and continued postoperatively until such time as the patient can take adequate amounts of fluid by mouth. Whatever procedure is carried out the average operating time is three hours.

At the end of the operation the throat packs are removed and the jaws are fixed in their new position using intermaxillary fixation with elastic bands on the splints.

\section{Postoperative management}

Some sedation is usually necessary for the first forty-eight hours, but patients are soon up and about.

All sutures are removed in four to six days. Elastic intermaxillary fixation is replaced by stainless steel wires. When the patients have learned to manage their semi-solid special diet and can keep their mouths and splints clean they go home on sick leave, usually for four weeks. The jaw fixation is removed when they return, careful prophylaxis is carried out by the dental hygienist and normal pain-free jaw movements rapidly return. Minor adjustments to the occlusion of the teeth may be necessary and they resume their normal diet. Patients are instructed to avoid vigorous games for three months and each patient is periodically reviewed. Final photographs and follow up radiographs are taken.

To date 54 of these operations have been performed at The Queen Alexandra Military Hospital, London, and at the Cambridge Military Hospital, Aldershot, and some results are shown (Fig. 4).

\section{Acknowledgements}

We thank Mr. T. G. Ward, Mr. N. L. Rowe, Mr. J. H. Hovell and Brigadier D. V. Taylor whose help and advice led to the development of this branch of facial surgery in the Army.

Grateful thanks are due to General Surgical colleagues, Anaesthetists, Theatre, Ward and Dental Department staffs. Without their willing help these operations could not have been performed.

\section{REFERENCE}

ObWegeser, H. (1963). Brit. J. oral Surg. 1, 157.

\section{R.A.M.C. Officers' Widows' \& Orphans' Friendly Society}

From 29th November 1969, the registered office of the above Society will be in the premises of Messrs. Glyn, Mills \& Co., 15 Whitehall, London, S.W.1. 